\title{
Course of angina pectoris after an acute coronary event
}

\author{
LESLIE E DALY， NOEL HICKEY， RISTEARD MULCAHY
}

\begin{abstract}
The course of postcoronary angina pectoris was examined in 555 men who had survived a first attack of myocardial infarction or unstable angina. Patients were aged less than 60 and were followed up yearly for up to 17 years. Only $25(4.5 \%)$ had coronary artery bypass surgery. Most patients with angina were treated by nitrates alone.

One year after infarction $24 \cdot 1 \%$ of survivors $(124 / 515)$ reported the presence of angina pectoris, and the proportions at five, 10, and 15 years were $29.9 \%, 30.4 \%$, and $43.5 \%$ respectively. Seventeen years after the initial event $35.3 \%$ of the survivors had never reported postcoronary anginal symptoms.

The patients who experienced anginal symptoms in the year after their coronary attack had a poorer long term survival than the group who were symptom free over the first year. These patients also had longer subsequent periods with angina, though in $41.7 \%$ angina resolved before death after a median of 2.9 years. Throughout follow up mortality during periods in which patients experienced angina was higher than in the symptom free periods.

This long term follow up study of patients after a coronary event confirms that the presence or absence of angina may vary considerably over time in patients treated medically and that the presence of angina is associated with a poorer prognosis. These findings have important implications when assessing the effects of various treatment modalities on postcoronary angina, including coronary artery bypass surgery.
\end{abstract}

Department of Community Medicine and Epidemiology, University College, Dublin 2, Ireland

LESLIE E DALY, MSC, PHD, lecturer in biostatistics

NOEL HICKEY, FRCPI, FFCMI, lecturer in epidemiology

Department of Preventive Cardiology, St Vincent's Hospital and University College, Dublin

RISTEARD MULCAHY, MD, FRCPI, professor of preventive cardiology

Correspondence and requests for reprints to: Professor R Mulcahy, Department of Preventive Cardiology, St Vincent's Hospital, Dublin 4, Ireland.

\section{Introduction}

Angina pectoris is common in survivors of acute myocardial infarction and prevalence estimates of the symptom in observational studies range from $20 \%$ up to $75 \% .^{1.7}$ Little is known, however, about the long term course of postcoronary angina.

This study examines the pattern of angina pectoris in 555 male survivors of a first attack of unstable angina or myocardial infarction for up to 17 years after the initial event.

\section{Patients and methods}

Between 1 January 1965 and 31 December 1975, 555 consecutive male patients aged under 60 who had survived 28 days after a first attack of unstable angina or myocardial infarction were entered into a long term follow up study (the St Vincent's heart study). Details of the study methods have been described. ${ }^{8}$ Diagnosis of myocardial infarction was based on a history of cardiac pain, fresh $\mathrm{Q}$ waves in the electrocardiogram, or a twofold or more increase in cardiac enzyme activities (creatine kinase, lactate dehydrogenase, and aspartate transaminase). Unstable angina was diagnosed in patients with cardiac pain, serial ST and T wave changes in the absence of fresh $\mathrm{Q}$ waves in the electrocardiogram, and the absence of evidence of recent myocardial necrosis, as manifested by normal or less than a twofold rise in cardiac enzyme values.

A full risk factor profile was determined for each patient on entry to the study and each patient was seen yearly at a special follow up clinic. At each follow up examination patients were seen by either NH or RM and the presence or absence of angina recorded. Angina was determined on the basis of a history of typical cardiac pain induced by exercise and relieved by rest. Date of death was ascertained for all those who died. A total of 282 patients had died by the end of 1983 and all but 11 of the survivors had had their last follow up attendance in 1982 or 1983. Thirty four early deaths (mean survival 32 weeks) occurred before postcoronary anginal state could be determined. The average duration of follow up to death or last contact was 8.8 years, with an average of $7 \cdot 3$ follow up examinations at which angina was recorded in each patient.

All patients were managed conservatively. $\beta$ Blockade was used only in severe angina to facilitate an exercise programme and was terminated when exercise capacity returned to a satisfactory level. Nitrates (sublingual and long acting) were the only antianginal treatment used routinely. Only 25 patients proceeded to coronary artery bypass surgery over the entire period of follow up.

For each patient the presence or absence of angina at yearly intervals from entry to the study was determined from the follow up examination closest to the exact anniversary date. Patients were also categorised at the examination on the basis of any current or previous postcoronary anginal symptoms (cumulative prevalence of angina). The proportion of the original total 
cohort with angina was obtained by multiplying the proportion of actual survivors with angina by the cumulative survival rate based on the KaplanMeier clinical life table' (these results are presented in figures 1-3). The proportion of patients who over a year either had a change in their anginal state (from, say, present to absent) or died was calculated for each yearly interval in those who were alive at the start of the interval and who were not withdrawn from the study during the period. These yearly estimates were averaged (weighting by the numbers alive at the start) to give the figures quoted in table III.

Determination of the pattern of postcoronary angina over time was based on the assumption that a patient had a change in his anginal state (from present to absent or absent to present) midway between two successive follow up examinations at which different anginal states were recorded. A patient remained in a particular anginal state until he died or his angina resolved or reappeared, whichever was the case. The median time a patient remained in an anginal state was estimated using a multiple decrement life table analysis ${ }^{10}$ which allowed for these two end points. ${ }^{9}$ The median time to change of anginal state was defined as that time when half of those whose state eventually changed (before death) had actually done so. Similarly half the patients who eventually died without a change in state had done so by the median time to death.

This analysis also allowed estimation of the proportion of patients (say, with angina present) who could be expected to die without resolution of their angina and the proportion whose angina would resolve (change of anginal state). Whereas the usual life table gives the proportion dead at the longest time that any patient was followed up, the multiple decrement life table gives the proportions who changed state and who died. Our estimate of the final proportion expected to die was based on the ratio of these two quantities. For example, if at the last time point of the life table we had $15 \%$ dead and $60 \%$ with a change of state, then $20 \%(15 / 75)$ of the total end points at that time (death or change of state) would be attributable to mortality. We thus estimated that eventually, if the life table could have been extended, $20 \%$ of the group would have died and $80 \%$ would have changed state.

Subsequent anginal patterns were determined separately in those who did and did not report angina at their first follow up attendance. For instance, the median times to death and resolution of angina were calculated first for the patients who had postcoronary angina at first follow up. The median times to death and reappearance of angina were then calculated in the subgroup whose angina had resolved. The analysis was next performed on those whose angina had reappeared and the process was repeated.

Standard errors (SE) for the cumulative survival were based on the equivalent sample size approximation, ${ }^{11}$ while the usual binomial formula was used for the proportions at yearly intervals in a category as a percentage of the survivors. Ninety five per cent confidence intervals were based on the normal approximation (with $1.96 \mathrm{SE}$ ) and are given in the text in parentheses. Owing to the difficulty of density function estimating ${ }^{12}$ standard errors were not determinable for the median times to death or change in anginal state and estimation of confidence intervals was not possible.

\section{Results}

Table I shows selected characteristics of the 555 patients at entry to the study. These are provided for comparison with patients included in other such studies and their influence on postcoronary angina is not considered here.

A total of 522 subjects $(94 \cdot 1 \%)$ were alive one year after the initial coronary attack. Seven died subsequently without follow up examination with a mean survival of 1.6 years. Of the remaining 515 subjects, $124(24 \cdot 1 \%)$ reported the presence of angina at one year and $391(75.9 \%)$ did not. Table II shows the number of subjects alive at intervals up to 17 years in the total group and in those with and without angina at year 1 . Figure 1 shows the yearly prevalence of angina over 17 years. Prevalence increased progressively from $24 \cdot 1 \%(20 \cdot 4-27 \cdot 8 \%)$ at one year to $29 \cdot 9 \%(25 \cdot 6-34 \cdot 2 \%)$ at five years and to $43 \cdot 5 \%(29 \cdot 2-57 \cdot 8 \%)$ at 15 years. Prevalence fell in the remaining two years. Figure 1 shows clearly that the increasing frequency of angina was due to a decreasing number of patients free of angina, with a relatively constant number of patients with angina. Table III presents the average proportions of patients whose anginal state changed or who died in a one year period, which explain this effect. Mortality was, in fact, higher in those with angina than in those without. Nevertheless, since at any period most patients did not have angina, the numbers developing angina tended to balance out the deaths and resolutions of angina in patients with angina originally.

The proportion of patients who had experienced any postcoronary angina (cumulative prevalence) increased steadily from $24 \cdot 5 \%(20 \cdot 8-28 \cdot 2 \%)$ at year 1 to $39 \cdot 2 \%(34 \cdot 5-43 \cdot 9 \%)$ at year 5 and to $64 \cdot 7 \%(42 \cdot 0-87 \cdot 4 \%)$ at year 17 . Hence over one third $(12 \cdot 6-58 \cdot 0 \%)$ of the patients who were alive 17 years after their attack had never reported anginal symptoms.
Of the 124 subjects with angina at year $1,96 \cdot 0 \%(92 \cdot 5-99 \cdot 5 \%)$ were alive at year 2 . In $9 \cdot 2 \%(3 \cdot 9-14 \cdot 5 \%)$ of these angina had resolved. The proportion of patients without angina increased to a maximum of $31 \cdot 3 \%(18 \cdot 2-44 \cdot 4 \%)$ 10 years after the attack and thereafter declined (fig 2). (Position of shading in figure 2 is reversed to highlight rise and fall of the proportions without angina.) Figure 3 shows the yearly prevalence of angina in the 391 patients who were free of angina one year after their coronary event. The survival of these patients was consistently better than that of those who had angina at one year. The five, 10 , and 15 year survival rates were $86 \cdot 3 \%(83 \cdot 0-89 \cdot 6 \%)$, $69 \cdot 0 \%(63 \cdot 3-74 \cdot 7 \%)$, and $40 \cdot 1 \%(30 \cdot 3-49 \cdot 9 \%)$ in the angina free group at one

TABLE I-Selected baseline characteristics in study of group of 555 survivors of coronary event. Except where stated otherwise figures are numbers (percentages) of patients

\begin{tabular}{lc}
\hline Mean (SD) age (years) & $50 \cdot 8(6 \cdot 4)$ \\
Severity of initial attack: & $102(18 \cdot 4)$ \\
Unstable angina & $453(81 \cdot 6)$ \\
Myocardial infarction & \\
Precoronary angina ${ }^{\star}:$ & $146(26 \cdot 5)$ \\
Present & $405(73 \cdot 5)$ \\
Absent & \\
First outpatient blood pressure reading (mm Hg): & $137 \cdot 7(20 \cdot 6)$ \\
Mean (SD) systolic & $87 \cdot 6(12 \cdot 3)$ \\
Mean (SD) diastolic & $6 \cdot 7(1 \cdot 4)$ \\
Mean (SD) serum cholesterol (mmol/1) & \\
Cigarette smoking: & $408(73 \cdot 5)$ \\
Current smokers & $98(17 \cdot 7)$ \\
Ex-smokers & $49(8 \cdot 8)$ \\
Never smokers &
\end{tabular}

* Missing in four patients.

Conversion: SI to traditional units-Cholesterol: $1 \mathrm{mmol} / \approx 38.6 \mathrm{mg}$ $100 \mathrm{ml}$.

TABLE II-Numbers of patients alive at selected times from entry to study

\begin{tabular}{cccc}
\hline $\begin{array}{c}\text { Time from initial attack } \\
\text { (years) }\end{array}$ & Angina at year 1 & No angina at year 1 & All patients \\
\hline 1 & 124 & 391 & $522^{\star}$ \\
5 & 98 & 333 & 431 \\
10 & 48 & 179 & 227 \\
15 & 8 & 38 & 46 \\
17 & 5 & 12 & 17 \\
\hline
\end{tabular}

^In seven patients anginal state at year 1 was undetermined.

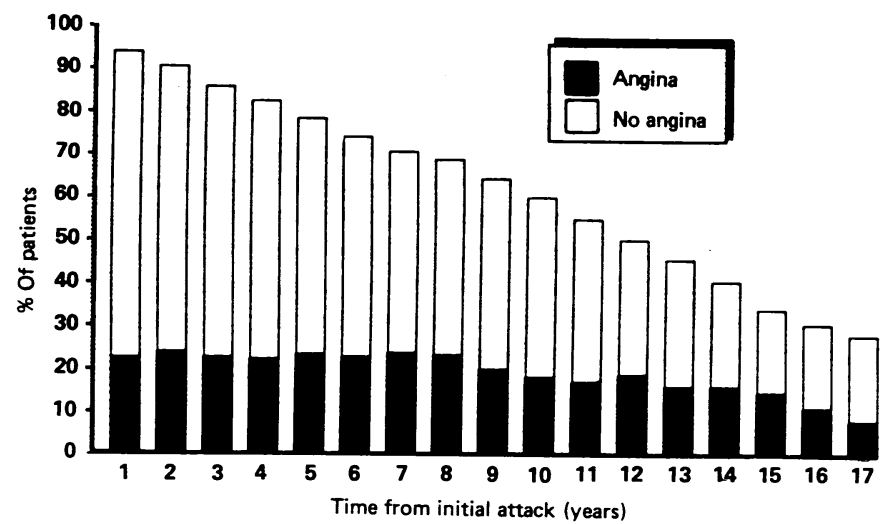

FIG 1-Subsequent prevalence of angina in 555 survivors of coronary attack. Columns represent percentage survival.

TABLE III-Percentages of patients dying or changing anginal state in successive yearly intervals (averaged over all periods)

\begin{tabular}{lcccc}
\hline & \multicolumn{3}{c}{ State one year later } \\
\cline { 2 - 4 } \multicolumn{1}{c}{ Anginal state } & Angina present & Angina absent & Dead & Total \\
\hline Angina present & $82 \cdot 8$ & $9 \cdot 8$ & $7 \cdot 4$ & $100 \cdot 0$ \\
Angina absent & $6 \cdot 4$ & $88 \cdot 8$ & $4 \cdot 8$ & $100 \cdot 0$ \\
& & & &
\end{tabular}




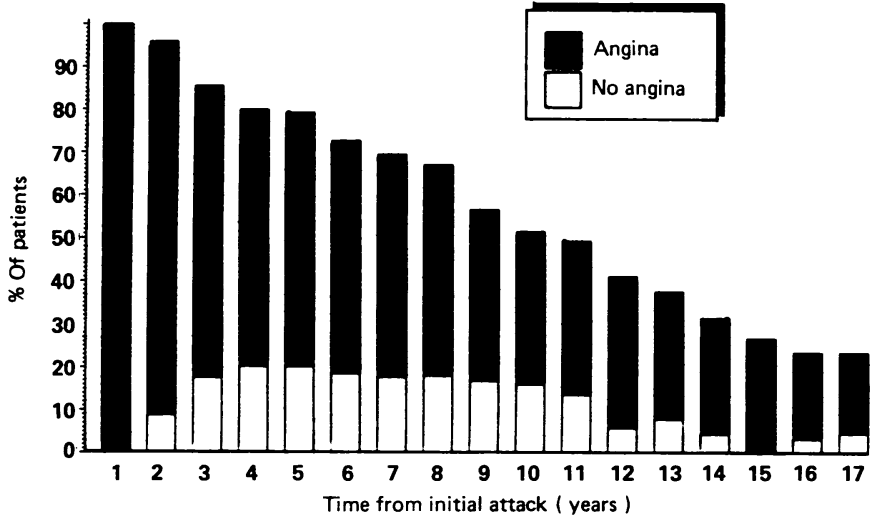

FIG 2-Subsequent prevalence of angina in 124 survivors of coronary attack who had angina at year 1 . Columns represent percentage survival.

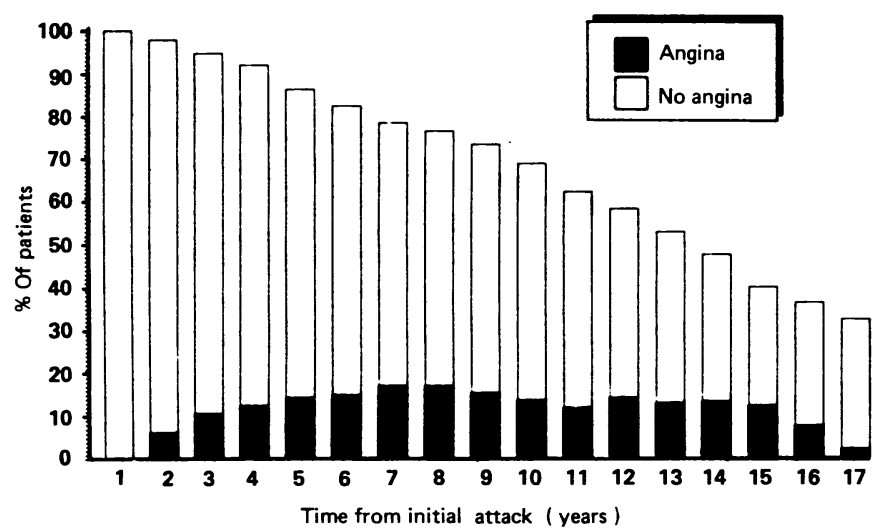

FIG 3-Subsequent prevalence of angina in 391 survivors of coronary attack who were free of angina at year 1 . Columns represent percentage survival.

year compared with $79 \cdot 0 \%(71 \cdot 7-86 \cdot 3 \%), 51 \cdot 4 \%(41 \cdot 2-61 \cdot 6 \%)$, and $26 \cdot 7 \%$ $(10 \cdot 8-42 \cdot 6 \%)$ in the angina group. Nevertheless, the proportion of patients initially free of angina who subsequently reported the symptom increased from $6 \cdot 5 \%(4 \cdot 0-9 \cdot 0 \%)$ at year 2 to $31 \cdot 6 \%(16 \cdot 9-46 \cdot 3 \%)$ at year 15 , falling somewhat during the remaining two years of follow up.

The duration and frequency of postcoronary angina were analysed in the 521 patients who survived to the first follow up examination. One hundred and thirty patients $(25 \cdot 0 \%)$ had angina at first examination and $391(75 \cdot 0 \%)$ did not. (Note that we are considering here all patients who were alive at their first follow up examination, not just the 515 who were alive at year 1 with follow up information.) Of those with angina, $58.3 \%$ continued to have angina up to the time of death a median of 8.5 years later (fig 4 ). Angina resolved in the remaining $41 \cdot 7 \%$ over a median of $2 \cdot 9$ years. Of these, $37.5 \%$ ( $12 \cdot 8 \%$ of the total) died without angina reappearing (median time to death

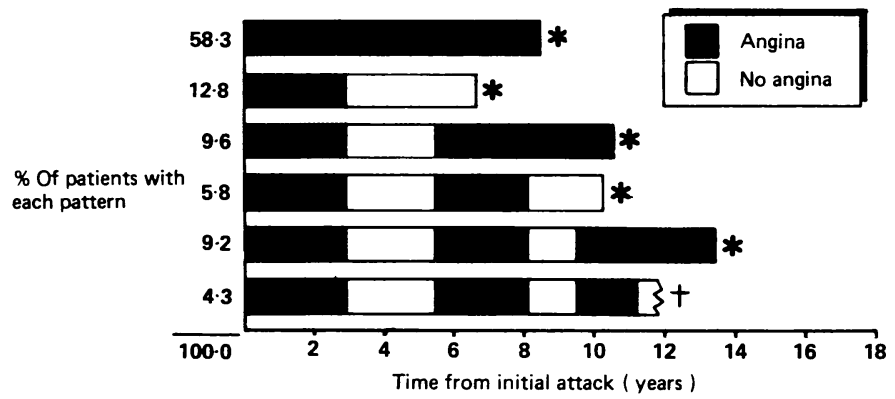

FIG 4-Median times in each anginal state in 130 survivors of coronary attack who had angina at first follow up examination.

$\star$ Death.

†Median time in last state not estimable. Two patients had no angina; both withdrew.
3.7 years after disappearance of angina). Of those with immediate postcoronary angina, $4 \cdot 3 \%$ had at least five subsequent changes of anginal state.

Figure 5 shows the longitudinal pattern of angina among the 391 patients initially free of angina. A total of $59.5 \%$ remained free of angina up to the time of death with a median survival of 12.3 years. Nearly $8 \%$ experienced five changes of anginal state during follow up.

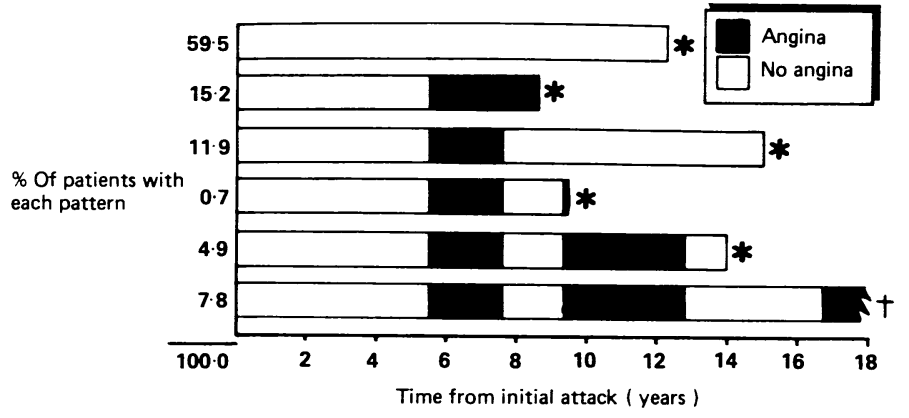

FIG 5-Median times in each anginal state in 391 survivors of coronary attack who were free of angina at first follow up examination.

^Death.

†Median time in last state not estimable. Four patients had angina; one died, three withdrew.

\section{Discussion}

Studies of postcoronary angina have concentrated on factors predicting its presence,,$^{1-35713}$ its relation to the severity of coronary artery disease, ${ }^{67}$ or the relation to subsequent morbidity and mortality. ${ }^{25} 14$ In most studies angina was determined within two years of the initial acute attack and differences in its ascertainment probably account for the large variation in reported prevalence rates. The Framingham study examined the cumulative prevalence of angina and reported figures of $21 \%$ one year after infarction and $33 \%$ at five years. ${ }^{4}$ These agree well with our figures of $25 \%$ and $39 \%$. Apart from these data, little has been reported about the pattern and distribution of postcoronary angina over time.

The analytical approach used here to study the course of angina for up to 17 years has not been employed previously. The data presented also conform well with a Markov statistical model. ${ }^{15}$ The ability to study the course long term was due to the uniqueness of the series of patients, who were managed by conservative medical treatment, risk factor intervention, and rarely bypass surgery, and who had exceptionally complete follow up information.

Some three quarters of survivors of a first coronary attack will not complain of angina one year later. After 15 years over half will still be angina free. Seventeen years after a coronary event over one third of patients will never have experienced symptoms of angina. The evanescent nature of angina was also apparent in this study. Of those with angina at one year, just under a third did not complain of angina at 10 years.

Patients with immediate postcoronary angina will experience fewer subsequent angina free periods than those who were symptom free initially. If angina does develop in this latter group it will be of relatively short duration compared with the angina free periods. The presence of angina immediately after infarction is related to increased long term mortality, and the mortality in patients with angina at any time is higher than in those without.

Though the conservative treatment of this series of patients may limit generalisations from our findings, the data do give a clear indication of the course of postcoronary angina. The present descriptive analysis does not, however, examine possible factors which may account for the changing anginal state of patients. Possibly the presence of angina compelled patients to reduce physical activity or give up work, with a consequent resolution of symptoms. The use of antianginal medication was not studied as a variable, nor was the influence of bypass surgery. A recent report on the same patients suggests, however, that both the absence of precoronary angina and stopping smoking were associated with a reduction in the frequency of postcoronary anginal symptoms. ${ }^{13}$ 
The presence of severe postcoronary angina has now become an accepted indication for surgical intervention and, though the data as presented here do not substitute for well controlled randomised trials, knowing the course of essentially untreated disease in an unselected group of patients can aid in the evaluation of such interventions.

This study was funded by University College, Dublin. We acknowledge the endeavours of all members of the research team in the cardiac department of St Vincent's Hospital who helped in the yearly follow up examinations. We are grateful to Mrs Christine Delaney for excellent typing and to the computer centre of University College, Dublin, for the use of facilities.

\section{References}

1 Wilhelmsson C, Vedin JA, Elmfeldt D, Tibblin G, Wilhelmsen L. Angina pectoris and myocardial infarction. Acta Med Scand 1977;202:337-40.

Kannel WB, Feinleib $M$. Natural history of angina pectoris in the Framingham study. Prognosis and survival. Am $\mathcal{F}$ Cardiol 1972;29:154-63.
3 Waters DD, Theroux P, Halphen C, Mizgala HF. Clinical predictors of angina following myocardial infarction. Am f Med 1979;66:991-6.

Kannel WB, Sorlie P, McNamara PM. Prognosis after initial myocardial infarction: the Framingham study. Am $\mathcal{F}$ Cardiol 1979:44:53-9.

5 Taylor GJ, O'Neal Humphries J, Mellits D, et al. Predictors of clinical course, coronary anaromy and left ventricular function after recovery from acute myocardial infarction. Circulaion $1980 ; 62: 960-70$.

6 Vanhaecke J, Piessens J, Willems JL, de Geest $\mathbf{H}$. Coronary arterial lesions in young men wh survived a first myocardial infarction: clinical and electrocardiographic predictors of multivessel disease. Am 7 Cardiol 1981;47:810-4.

7 Midwall J, Ambrose J, Pichard A, Abedin Z, Herman MV. Angina pectoris before and after myocardial infarction. Chest 1982;81:681-6.

8 Mulcahy R, Hickey N, Graham I, McKenzie G. Factors influencing longterm prognosis in male patients surviving a first coronary attack. Br Heart $\mathcal{F}$ 1975;37:158-65.

9 Kaplan EL, Meier P. Nonparametric estimation from incomplete observations. Foumal of the American Statistical Association 1958;53(1):457-81.

10 Dorn HF. Methods of analysis for follow-up studies. Hum Biol 1950;22:238-48.

11 Peto R, Pike MC, Armitage P, et al. Design and analysis of randomised clinical trials requiring prolonged observations of each patient. II. Analysis and examples. Br f Cancer 1977;35:1-39.

12 Miller RG. Survival analysis. New York: Wiley, 1981.

3 Daly LE, Graham IG, Hickey N, Mulcahy R. Does stopping smoking delay the onset of angin after infarction? Br Med f 1985;291:935-7.

14 Schuster EH, Bulkley BH. Early post-infarction angina: ischemia at a distance and ischemia in the infarct zone. N Englf Med 1981;305:1101-5.

15 Howard RA. Dynamic probabilistic systems. Vol 1. Markoo models. New York: Wiley, 1971.

(Accepted 26 fune 1986)

\title{
Preventable childhood deaths in Wolverhampton
}

\author{
ANGELA MOORE
}

\begin{abstract}
A retrospective survey was undertaken of all deaths in children under 5 in the borough of Wolverhampton over the years 1976-82. Cause of death was classified in terms of preventability and possibly preventable deaths studied in more detail. Birth weight in the study group was significantly lower than that of the local population; there was no difference in ethnic origin, but there were significantly more Asian girls than Asian boys. The association between potentially preventable death and various socioeconomic indicators in the electoral wards in the borough was investigated. A significant association was found between mortality and overcrowding, lack of household amenities, unemployment, lack of car ownership, and households where the head was born in the new Commonwealth or Pakistan.
\end{abstract}

\section{Introduction}

In 1976 Wolverhampton was among the highest ranking local authority areas in England for perinatal and infant mortality. ${ }^{1}$ Along with all other areas in England and Wales the mortality rates for all ages have declined since then, but in 1980 there was a sharp increase in mortality under 5 years of age in Wolverhampton, particularly for sudden infant deaths, which prompted this inquiry.

The lower child mortality rates in Scandinavian countries compared with Britain reflect their lower death rates from causes such as "acute infections," "cot deaths," and "treatable" diseases, while death rates from causes such as congenital heart disease are similar throughout northern Europe. ${ }^{2}$ Reliable data on the causes of death

\footnotetext{
Department of Paediatrics, New Cross Hospital, and Community Health Services, Wolverhampton

ANGELA MOORE, MRCP, senior clinical medical officer

Correspondence to: Department of Paediatrics, New Cross Hospital, Wolverhampton WV10 0QP.
}

in childhood depend on specialist paediatric pathologists, and in parts of Britain where these are available the true rate of unexplained cot deaths may be similar to that in Finland and Sweden. ${ }^{3}$

It has been suggested that the prevention of deaths from treatable diseases in Britain is dependent on improvement in our primary health care and that a regular system of inquiry into child deaths should be an essential part of child health surveillance. ${ }^{2}$ The Black report established the need for further work on the relations between indicators of social disadvantage and mortality. ${ }^{1}$ This study describes the overall pattern and preventable causes of child mortality in a mixed urban population in the West Midlands and explores some of the environmental and social factors that may be implicated.

\section{Subjects and methods}

Deaths in childhood occurring during 1 January 1976 to 31 December 1982 were studied retrospectively. Any child under 5 whose parents' place of residence was within the Wolverhampton district and whose death was registered in Wolverhampton was included. The population of Wolverhampton Metropolitan Borough is about a quarter of a million, from which there are roughly 3500 births each year.

Cases were identified by searching the Registrar's returns. Each death was classified in terms of preventability in a similar way to that suggested by Taylor and Emery ${ }^{3}$ (see appendix). In view of the difficulty in judging retrospectively whether a particular death might have been prevented, only deaths in group A (diseases with a very poor prognosis) were regarded as inevitable and all the others as possibly preventable. A more detailed study of potentially preventable deaths was undertaken in an attempt to identify the characteristics of this group where increased use of resources might have averted death.

Information was taken personally from community health records including health visitors' notes and obstetric, paediatric, and casualty records. Notes were made of sex, birth weight, ethnic origin, infant feeding practice, clinic attendances, area of residence, and "adverse social factors." Adverse social factors included one or more the following: mother aged less than 20; single parent or absent father (in prison, working away, etc); dirty, overcrowded home or other housing problems; financial difficulties; inadequate child care or refusal of health advice; child minded or fostered, or either considered; behavioural problems in child; psychiatric illness in 